\title{
EMPIRICAL ECONOMETRIC MODEL OF AN ENTERPRISE
}

\author{
Prof. Jerzy Witold Wiśniewski \\ Nicolaus Copernicus University in Torun \\ Department of Econometrics and Statistics \\ Gagarina 13A, 87-100 Toruń, Poland \\ e-mail: Jerzy.Wisniewski@umk.pl
}

Received 3 November 2015, Accepted 22 June 2016

\begin{abstract}
This work will present an empirical econometric model describing an enterprise within the category of medium-sized companies (according to European Union classification). The company, code-named ENERGY, carries out a manufacturing, commercial, and service business activity. The statistical data used was in the form of quarterly time series, containing 24 statistical observations from the years 2008-2013. A hypothetical model of the enterprise is a system of interdependent equations.

The econometric model is composed of seven stochastic equations. The empirical model is missing the equation describing investments in the enterprise. It results from the fact, that during the years 2008-2013 the company suffered meagre investments. Investment output equation, therefore, does not provide any relevant systemic information for the management, since most statistical information in the time series assumes zero values. An empirical model of the company ENERGY is a system of interdependent equations, with statistically significant feedback between labour efficiency (EFEMP) and the average pay per 1 employee (APAY). Additionally, there is recurrence of the relationships between the fixed assets (FIXAS), employment volume (EMP), and the size of the net sales income (SNET).

The empirical equations of the model are characterized by a description accuracy of individual endogenous variables. The model also has good decision-making and forecasting qualities.
\end{abstract}

Keywords: econometric micromodel, microeconometrics, empirical model, enterprise, production

JEL classification: C30,C32, C51, C53, D24 


\section{Introduction}

The important area of application of econometric methods are comprehensive studies of the manufacturing processes in the companies. The necessity of undertaking rational decisions and operations by the entrepreneur requires their knowledge about a cause and effect relationship occurring between the various important economic variables in the company. The description of the enterprise using the econometric model with many equations allows the rationalization of management decisions. It also helps to predict future values of the variables included in the modeled economic system.

The economic literature is poor of works which present model solutions for the companies described by multi-equation econometric models. Therefore, there is a large gap in the literature. It results from the fact that theorists do not have access to detailed databases of the specific companies. The practitioners, from the other side, are not aware of the existence of the econometric tools that could efficiently support the decision-making processes in the enterprises. The main goal of this paper is to fill this gap in the literature.

The main goal of this study was the attempt to design an empirical econometric model of medium-sized enterprises. The enterprise which is described by the statistical data is characterized by the mixed business profile. It operates in service, commercial, and production profile. It belongs to the energy industry. It has been extracted from a large energy company. The construction of a multi-equation econometric model is based on the diagram of the interdependent relations of economic variables, which decide about the business profile of the company. The parameters of each model's equations were estimated using ordinary least squares method. The arguments supporting application of this method can be found in the work of Wisniewski (2011) and Goldberger (1972).

\section{Economic interrelations in an enterprise}

In a company-management practice, strong multilateral relationships between various economic processes exist. Such links occur only within a company. They are subject to the influence of various external factors. A mechanism of economic links that occur in large- and medium-sized enterprises is presented in Figure $1 .^{1}$

\footnotetext{
1 A prototype of the presented here mechanism of interconnections in an enterprise was used in the work of J.W. Wiśniewski and Z. Zieliński (1989), p. 44.
} 
Production is the final process described in a mechanism of interrelations in a large (medium $)^{2}$ enterprise. This type of a company has a complex structure containing specialized services, which deal with individual elements occurring in Figure 1. The concept of production here will be understood as the sum of net ${ }^{3}$ sales income. Production of finished goods is subordinate to a generated demand for company's goods and services, as observed by marketing services. The execution of liabilities for sold goods (services) is dealt with by debt recovery specialists. Therefore, a time interval between the manufacture of goods (production of a service), its invoicing, and receiving a payment from a client is relatively short. It can be assumed, that it is a period negligible from the perspective of a large enterprise's operation time.

Production volume results from the impact of human labor, presented in the model by employment magnitude, and the efficiency of live-labor inputs, as well as from the activity of services concentrated within the field specified as marketing. Marketing can be regarded as an instrument created within an enterprise, where it can be applied as a management tool used, among other things, for production volume formation.

Employment is a variable inside a company, which influences its final result. It is also a subject to the influence of factors, some of which are located within the enterprise, and other outside it. The second of the important production factors - efficiency of labor input (labor productivity) - is similar in character. Efficiency depends on the conditions inside the company as well as outside it. What draws attention, is feedback between the efficiency of live-labor input and the competitiveness of working conditions $s^{4}$ of an enterprise. This signifies a simultaneous reciprocal influence of the pair of variables mentioned here. The level of technology and production organization, located within the term technological-organizational progress, is an important agent in efficacy of a labor factor.

The widely interpreted competitiveness of working conditions of an enterprise is shaped by many factors. Two particularly important ones are shown here: staff qualifications as well

\footnotetext{
2 We skip here the definitions relating to the isolation of a term 'large' (medium) enterprise. Legal definitions can be found in adequate legal acts (bills). Economic definitions can be found in enterprise literature (i.e. in S. Sudol, 2002). A significant amount of statistical information characterizing the activity of a large sized enterprise must come from account books, which are obligatorily kept by such companies.

3 Net sales income comprises the enterprise's actual property. Gross sales income includes the tax on goods and services, which belongs to the state.

${ }^{4}$ Working-conditions competitiveness in an enterprise is a complex characteristic (multidimensional). It can be comprised of such simple features as: salary amount, company's prestige, market position, which is decisive for a low lay-off risk, possibility of the so called self-realization of an employee, worker benefits, possibility of traveling to interesting places, etc.
} 
as the autonomous process of living-conditions improvement ongoing outside the enterprise, ${ }^{5}$ independently of its inside processes.

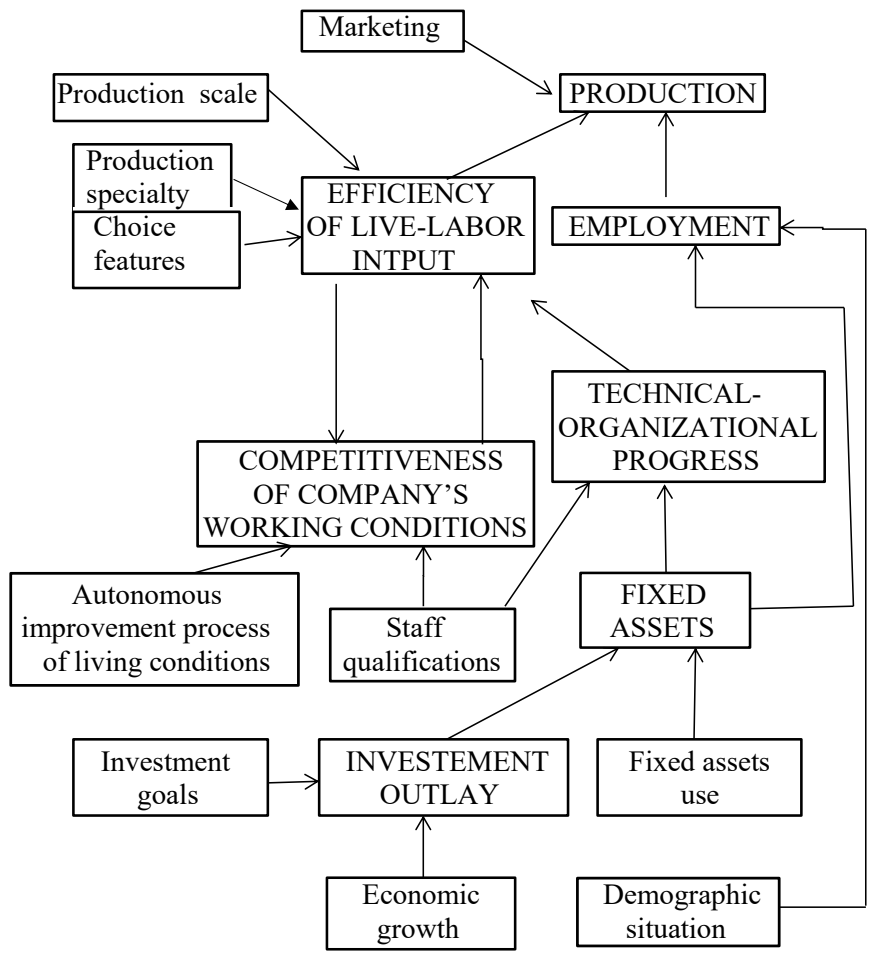

Figure 1. Economic interrelations in a large- (medium-) sized enterprise

Source: Wiśniewski (2003). ${ }^{6}$

Employment volume is shaped, above all, by the available fixed assets. Complementarity and substitutability relations occur between employment and fixed assets. This means, that the increment of the company's fixed assets can cause employment increase (complementarity) or decrease (substitution). Generally, in an enterprise, complementarity and substitution occur simultaneously. Changes in employment volume are the outcome of these processes.

\footnotetext{
5 Manifestation of this can be: minimum wage increase, high dynamics of economy, which increases employment demand. As a result, its price goes up (the wage).

${ }^{6}$ The mechanism of interdependencies between economic variables in a large- and medium-sized enterprise can differ in its details, depending on the business type, the country in which it conducts its business, and many more other characteristics. Figure 1 presents universal, general dependencies in this category of companies, especially of an industrial character.
} 
Enterprise's fixed assets undergo physical and moral (economic) consumption, thus, it must be regenerated. It follows, that the assets consumption causes quantitative and qualitative changes in the mass of those assets. On the other hand, enterprise's development requires investment outlays, which increase and modify the company's existent fixed assets.

Investment outlays result from a general atmosphere in the economy and within the country, as those can cause inclinations to invest or to refrain from such projects. Economic growth, being the most synthetic conceptualization of given area's economic conditions in a given time period, is an expression of that economic and national climate. The size and structure of investment outlays are determined by the needs and opportunities arising from the progressive consumption of fixed assets, as well as by the defined within a company goals, which are later on transferred into the language of company's investment objectives.

\section{Variable of an econometric model of a large- and medium-sized enterprise}

Econometric model's endogenous variables describing a large- (medium-) sized enterprise can be as follows: ${ }^{7}$

$\mathrm{Y}_{1}$ - net sales income of an enterprise (in millions $\left.\mathrm{PLN}\right)^{8}$ for a $t(\mathrm{t}=1, \ldots, \mathrm{n})$ time-period,

$\mathrm{Y}_{2}$ - the average annual ${ }^{9}$ number of employees, in full time equivalent,

$\mathrm{Y}_{3}$ - labor productivity calculated as the ratio ${ }^{10}$ of $Y_{1} / Y_{2}$

$\mathrm{Y}_{4}$ - average monthly wage, in PLN monthly ${ }^{11}$ for 1 employee,

$\mathrm{Y}_{5}$ - initial value of active fixed assets, in millions PLN,

$\mathrm{Y}_{6}$ - technical labor devices measured by the initial value of the fixed assets, for 1 employee (in thousands PLN/1 employee), adjusted by a shift coefficient,

$\mathrm{Y}_{7}$ - value of investment outlays in a $t$ period, i.e. in thousands PLN.

\footnotetext{
7 Differences in the purposes of econometric model construction can influence the constructional variety of relationship patterns between important economic categories. The degree of detail in the approach to the description of a large-sized enterprise can vary. Thus, it is necessary to consider a variety of sets of endogenous and exogenous variables in such econometric model.

${ }^{8}$ Depending on the type of time series, it can be the annual, quarterly, or monthly net sales income. The time variable t can signify a number of the year, the quarter, or the month.

9 Depending on the type of data, it can be the average quarterly or average monthly number of employees, measured in full-time job positions.

${ }^{10}$ In the denominator, the variable $Y_{1}$ - for the purpose of measuring labor efficiency - should be defined as the value of production preformed in $t$ period.

${ }_{11}$ Competitiveness of work conditions is described by an average monthly wage, because it is the most understandable in the market category for the potential candidates for employment in an enterprise, considered for annual, quarterly, as well as monthly data.
} 
The following can be exogenous variables of a model for a large- (medium-) enterprise: $\mathrm{X}_{1}-$ cost of marketing activity, ${ }^{12}$

$\mathrm{X}_{2}$ - production volume in a natural measure unit, ${ }^{13}$ i.e. in thousands of tons, $\mathrm{X}_{3}$ - number of manufactured product range; production entropy $H t$ in a $t(\mathrm{t}=1, \ldots, \mathrm{n})$ period can be an alternative and is calculated using the following formula:

$$
H_{t}=\sum_{i=1}^{m_{t}} p_{t i} \log _{2} p_{t i}
$$

where $p_{t i}$ represents the share of $i$-th product range $\mathrm{e}^{14}$ in production value, whereas $m_{t}$ is the number of manufactured assortments in a $t$ period.

$\mathrm{X}_{4}$ - value of special-order production ${ }^{15}$ in millions PLN,

$\mathrm{X}_{5}$ - number of employees with higher education, ${ }^{16}$

$\mathrm{X}_{6}-$ annual depreciation of fixed assets ${ }^{17}$ in millions PLN,

$\mathrm{X}_{7}-\mathrm{GDP}^{18}$ growth rate,

$\mathrm{X}_{8}$ - number of the unemployed having qualifications necessary in the company, who are on the market on which the company ${ }^{19}$ functions,

$\mathrm{X}_{9}$ - value of sales on new markets, ${ }^{20}$ in millions PLN,

$\mathrm{X}_{10}$ - time variable ${ }^{21} t(\mathrm{t}=1, \ldots, \mathrm{n})$.

\footnotetext{
12 The category of marketing allows to generate a large variety of endogenous and exogenous variables in an econometric model of an enterprise. The role of a variable representing marketing can be fulfilled by e.g. commercial expenses, amount of taxes paid for participation in fairs, etc.

13 The variable expressed in a natural measure unit can be easily used in the case of production as a homogenous one, e.g. coal mining volume, beer production in million hectoliters, tonnage of manufactured ships. In the case of diverse manufacture, production scale can be represented by e.g. the volume of basic ram materials consumption expressed in physical units.

${ }_{14}$ The more ranges of products, the lower the level of production specialization. The variable $\mathrm{X}_{3}$ can be defined as e.g. $\mathrm{X}_{3}=H_{t}$.

${ }_{15}$ The category of product features can be represented by many other exogenous variables, e.g. the value of special equipment in non-standard products, etc.

${ }^{16}$ The variables representing staff qualifications can be defined in different ways. It is important for such variable to reflect those qualifications of employees which are most important for the company's efficiency.

${ }_{17}$ A variable such defined, representing fixed assets' consumption, exhibits streaming of its consumption for a given time period. However, it can turn out, that the value of fixed assets' redemption in a t period, a percentage of the net assets' value in the initial value, or the average age of the fixed assets, all can be better representatives of such consumption.

${ }^{18}$ GDP growth rate in $\mathrm{t}$ period contains information about the economic situation, which can increase the tendency to invest or limit it.

19 Obviously, there are other variables representing a demographic situation, e.g. number of working-age population in the company's employment area.

20 This variable represents the category of investment policy aims. The expansion onto new markets requires appropriate investment decisions, which result in an investment outlay increase. Investment policy aims can be represented by various variables, i.e. the value of new product ranges, various dummy variables representing the goal verbally defined. ${ }^{21}$ The time variable occurring in the equation describing wages is a carrier of an autonomous wage increase. Time variable can also occur in other equations of the model if there is a trend in the dependent variable.
} 
The econometric model is composed of seven stochastic equations. Compared to the hypothetical one presented in sub-chapter 3.2 (Wiśniewski, 2016), the equation describing company's investments is missing. This results from the fact, that in the years 2008-2013, the company suffered meager investment. The investment equation, thus, does not bring any significant systemic information to the area of company's management, because most statistical information in time series takes zero values. Therefore, the following endogenous variables will be described in the model:

SNET - quarterly net sales income (in millions PLN),

EMP - average quarterly employment, in full-time job positions (number of job positions),

EFEMP - labor productivity, per 1 quarterly full-time employee (in thousands PLN/1 employee),

APAY - gross average quarterly wage, per 1 employee (in thousands PLN),

FIXAS - company's average quarterly fixed assets value (in millions PLN),

PAY - payroll (in thousands PLN),

TAL - technical labor equipment measured in company's fixed assets, per 1 full-time employee (in thousands PLN/1 employee).

\section{Equation of the sales income}

The final equation of the model describes the volatility mechanism of the sales income.22 In the initial stage, a linear equation was used. Autoregressions up to and including the fourth order, a linear trend, as well as dummy variables were considered. Additionally, the size of employment, as well as the current and the delayed from 1 to 4 quarters values of fixed assets, were taken into account. An empirical equation describing the variable SNET, with good stochastic characteristics, excluding autocorrelation of the residuals, resulted from the elimination of statistically insignificant explanatory variables. A negative autocorrelation of the residuals (rho1 $=-0.410972$ ) occurred, which suggests an excess of explanatory variables in the empirical equation. The reduction of subsequent explanatory variables, which was also carried out, did not produce the expected results from the perspective of the decision-making suitability of the equation.

\footnotetext{
${ }_{22}$ The empirical econometric model of an enterprise presented in this work only partially reflects the mechanisms of interrelations between the variables that are presented in Figure 1. It is an alternative to the model presented in the work of Wiśniewski (2016).
} 
An attempt was made to construct a non-linear equation, using the same set of explanatory variables that was used in the linear equation. As a result of the reduction of subsequent statistically insignificant variables, an empirical equation of a ratio nature:

$$
\begin{gathered}
S N E T_{t}=\underset{(11.379)}{30178.95} \underset{(6.761)}{E M P_{t}^{0.498}} \underset{(3.106)}{S N E T_{t-3}^{-0.334}} \underset{(7.276)}{0.654^{d q 1}} \underset{(2.303)}{1.165^{d q 3}} e^{u \text { snet }} \\
R_{S N E T}^{2}=0.882, \text { rhol }=-0.030562
\end{gathered}
$$

Autoregression of the third order and a positive impact of employment on net sales income turned out to be statistically significant. Additionally, negative seasonal fluctuations in the first quarter, and positive seasonal fluctuations in the third quarter occur. The equation fits very well with the actual data $\left(R_{S N E T}^{2}=0.882\right)$. The application of Quenouille's test has evidenced that there is no autocorrelation of residues of the model. Accordingly, equation (2) can be used in decision-making processes. Volatility variations of the empirical and theoretical values are illustrated in Figure 2.

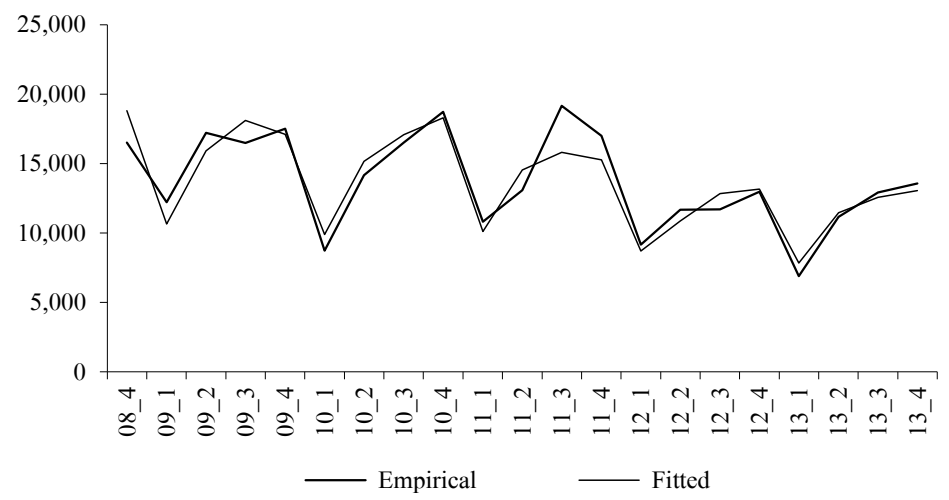

Figure 2. Sales income of an enterprise (thousands PLN)

Source: own calculations using the GRETL package.

\section{Equations of the manufacturing potential}

The next two equations will describe volatility mechanisms of employment (EMP) and of fixed assets (FIXAS). The empirical equation is presented in Table 1 and Figure 3. 
Table 1. Equation of the dependent variable (Y): EMP

\begin{tabular}{|l|c|c|c|c|c|}
\hline \multicolumn{1}{|c|}{ Variable } & Coefficient & Std. Error & t-Statistic & \multicolumn{2}{c|}{ p value } \\
\hline const & -45.488400 & 15.238500 & -2.9851 & 0.0092 & $* * *$ \\
\hline FIXAS & 5.605420 & 1.806350 & 3.1032 & 0.0073 & $* * *$ \\
\hline FIXAS_4 & 3.340920 & 1.542730 & 2.1656 & 0.0469 & $* *$ \\
\hline EMP_1 & 1.404970 & 0.176020 & 7.9819 & $<0.0001$ & $* * *$ \\
\hline EMP_2 & -0.736163 & 0.150354 & -4.8962 & 0.0002 & $* * *$ \\
\hline Mean dependent variable & 126.034000 & Stand.dev.dep.variable & 42.255540 \\
\hline Sum squared resid. & 149.199800 & S.E. of regression & 3.153832 \\
\hline R-squared & \multicolumn{2}{|c|}{0.995602} & Adjusted R-squared & 0.994429 \\
\hline F(4, 15) & 848.925500 & p-value for F-test & $1.79 \mathrm{e}-17$ \\
\hline Log likelihood & -48.474310 & Crit. inform. Akaike & 106.948600 \\
\hline Crit.Bayes. Schwarz & 111.927300 & Crit. Hannan-Quinn & 107.920500 \\
\hline Autocor.resid.coef.- rho1 & 0.065042 & Durbin h-stat. & 0.471655 \\
\hline
\end{tabular}

Source: own calculations using the GRETL package.

Employment autoregressions of the first and second orders are observed, wherein autoregression of the second order is negative in character, which mainly results from a systematic decrease in the size of employment in the company. The positive impact of the current and the delayed by four quarters fixed assets on the employment in the company occurs as well. This signifies the dominance of live-labour and capital complementarity in the analysed company. The equation highly accurately describes the volatility mechanism of employment, as evidenced by a high value of the R-squared factor, which exceeds $99 \%$. There is no autocorrelation of the equation's residuals.

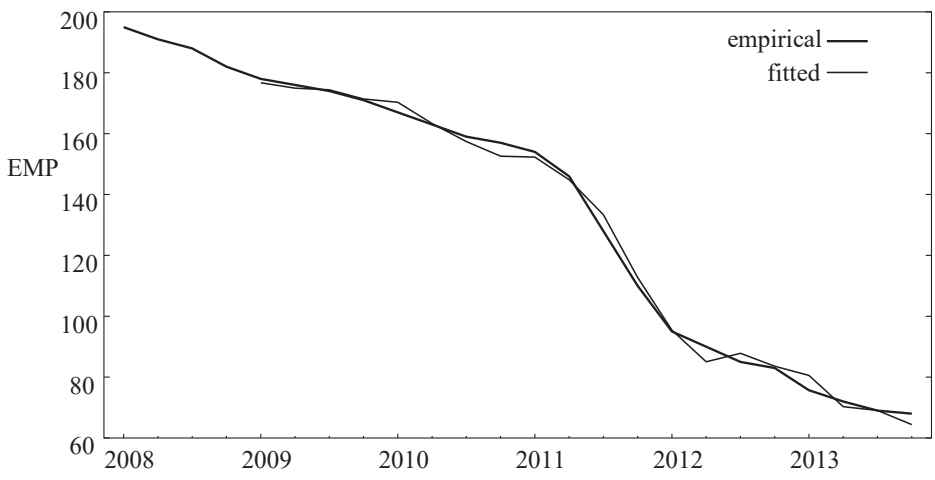

Figure 3. Empirical and fitted values of variable: EMP

Source: own calculations using the GRETL package. 
The empirical equation describing volatility of the fixed assets is presented in Table 2 and Figure 4. A radical reduction of explanatory variables occurred in the equation, which only leaves a negative linear trend and a negative autoregression of the fourth order. The equation highly accurately describes volatility of the variable FIXAS, since R-squared is over 98.6\%. Additionally, no significant autocorrelation of residuals can be observed. Equation of the fixed assets can be a good tool for estimating short-term forecasts of the value of the company's fixed assets. During the analysed period, a significant decrease in the value of the company's fixed assets occurs. The main reason for this trend is the lack of investments in the company.

Table 2. Equation of the dependent variable (Y): FIXAS

\begin{tabular}{|l|c|c|c|c|c|}
\hline \multicolumn{1}{|c|}{ Variable } & Coefficient & Std. Error & t-Statistic & \multicolumn{2}{c|}{ p value } \\
\hline const & 15.786000 & 0.9550580 & 16.5288 & $<0.0001$ & $* * *$ \\
\hline time & -0.311387 & 0.0165166 & -18.8530 & $<0.0001$ & $* * *$ \\
\hline FIXAS_4 & -0.168128 & 0.0717022 & -2.3448 & 0.0314 & $* *$ \\
\hline Mean dependent variable & \multicolumn{2}{|c|}{9.545000} & Stand.dev.dep.variable & 1.654491 \\
\hline Sum squared resid. & 0.683346 & S.E. of regression & 0.200491 \\
\hline R-squared & \multicolumn{2}{|c|}{0.986861} & Adjusted R-squared & 0.985315 \\
\hline F(2, 17) & 638.435800 & p-value for F-test & $1.02 \mathrm{e}-16$ \\
\hline Log likelihood & 5.386097 & Crit. Inform. Akaike & -4.772193 \\
\hline Crit.Bayes. Schwarz & -1.784996 & Crit. Hannan-Quinn & -4.189061 \\
\hline Autocor.resid.coef.- rho1 & 0.289089 & Durbin-Watson stat. & 1.417962 \\
\hline
\end{tabular}

Source: own calculations using the GRETL package.

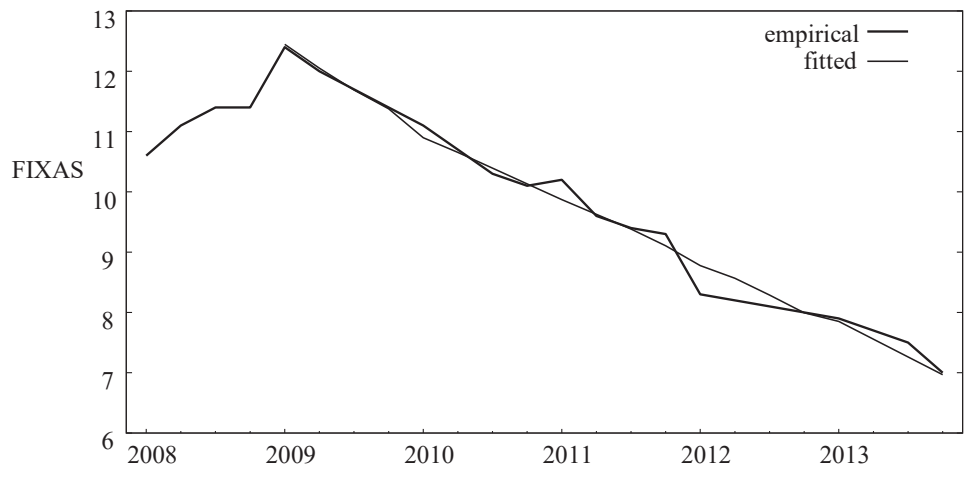

Figure 4. Empirical and fitted values of variable: FIXAS

Source: own calculations using the GRETL package. 


\section{Equations of labour efficiency and average pay}

The following pair of equations, which theoretically remain in feedback, is formed by the equations describing labour efficiency (EFEMP) and an average pay in the company (APAY). The empirical equation of labour efficiency is presented in Table 3 and Figure 5. It describes volatility of labour efficiency with a high accuracy, since R-squared exceed the level of $92.5 \%$. It also lacks autocorrelation of residuals. It turns out, that simultaneous and the delayed by three quarters average pay value positively impacts labour efficiency, being a positive occurrence.

Table 3. Equation of the dependent variable (Y): EFEMP

\begin{tabular}{|c|c|c|c|c|c|c|}
\hline Variable & Coefficient & \multirow{2}{*}{\multicolumn{2}{|c|}{$\begin{array}{c}\text { Std. Error } \\
17.23250 \\
\end{array}$}} & t-Statistic & \multicolumn{2}{|c|}{$\mathrm{p}$ value } \\
\hline const & 25.91490 & & & 1.5038 & 0.1534 & \\
\hline APAY & 1.87420 & \multicolumn{2}{|c|}{0.796887} & 2.3519 & 0.0328 & $* *$ \\
\hline APAY 3 & 3.17544 & \multicolumn{2}{|c|}{1.346540} & 2.3582 & 0.0324 & $* *$ \\
\hline time & 2.81673 & \multicolumn{2}{|c|}{0.671755} & 4.1931 & 0.0008 & $* * *$ \\
\hline dq1 & -47.21600 & \multicolumn{2}{|c|}{7.130410} & -6.6218 & $<0.0001$ & $* * *$ \\
\hline $\mathrm{dq} 2$ & -16.61690 & \multicolumn{2}{|c|}{6.967780} & -2.3848 & 0.0307 & $* *$ \\
\hline Mean dependent variable & \multicolumn{2}{|c|}{115.947000} & \multicolumn{2}{|c|}{ Stand.dev.dep.variable } & \multicolumn{2}{|c|}{39.52821} \\
\hline Sum squared resid. & \multicolumn{2}{|c|}{2328.681000} & \multicolumn{2}{|c|}{ S.E. of regression } & \multicolumn{2}{|c|}{12.45975} \\
\hline R-squared & \multicolumn{2}{|c|}{0.925481} & \multicolumn{2}{|c|}{ Adjusted R-squared } & \multicolumn{2}{|c|}{0.900642} \\
\hline $\mathrm{F}(5,15)$ & \multicolumn{2}{|c|}{37.258300} & \multicolumn{2}{|c|}{$\mathrm{p}$-value for F-test } & \multicolumn{2}{|c|}{$6.12 \mathrm{e}-08$} \\
\hline Log likelihood & \multicolumn{2}{|c|}{-79.237330} & \multicolumn{2}{|c|}{ Crit. Inform. Akaike } & \multicolumn{2}{|c|}{170.4747} \\
\hline Crit.Bayes. Schwarz & \multicolumn{2}{|c|}{176.741800} & \multicolumn{2}{|c|}{ Crit. Hannan-Quinn } & \multicolumn{2}{|c|}{171.8348} \\
\hline Autocor.resid.coef.- rhol & \multicolumn{2}{|c|}{-0.202350} & \multicolumn{2}{|c|}{ Durbin-Watson stat. } & \multicolumn{2}{|c|}{2.387806} \\
\hline
\end{tabular}

Source: own calculations using the GRETL package.

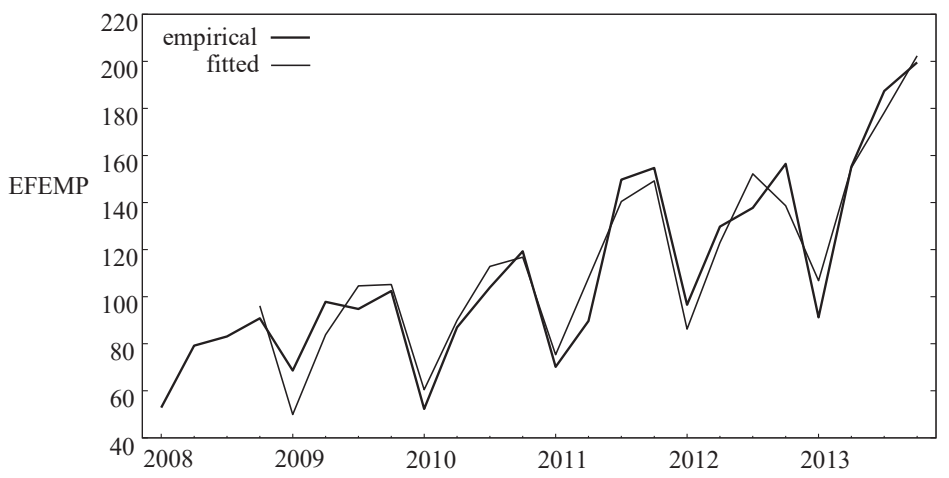

Figure 5. Empirical and fitted values of variable: EFEMP

Source: own calculations using the GRETL package. 
An upward linear trend in labour efficiency is beneficial as well. Furthermore, negative seasonal fluctuations of labour efficiency during the first and second quarters are observed, which results from the specificity of the industry in which the company operates.

The linear empirical equation describing an average pay (APAY) exhibits numerous defects. First of all, a negative autocorrelation of residuals occurred, distorting the correlation, due to deterioration of the precision (effectiveness) of the structural parameters' estimates. Therefore, an attempt was made to use a ratio form of the equation. As a result, an empirical equation of a power-exponential character emerged, written as the formula (3):

$$
\begin{aligned}
& A P A Y_{t}=\underset{(0.472)}{1.385} \underset{(8.506)}{\operatorname{EFMP} P_{(5.159}^{1.159}} \operatorname{APAY}_{t-4}^{-1.329} 1_{(4.425)}^{1.578^{d q 1}} e^{u_{A P A Y}} \\
& R_{A P A Y}^{2}=0.831, \quad D W_{A P A Y}=2.026
\end{aligned}
$$

Equation (3) explains $83.1 \%$ of the average pay's volatility. In an equation of a micromodel, it is a very good result. There is no autocorrelation of residuals. The actual and theoretical values of the average pay, calculated on the basis of equation (3) are presented in Figure 6.

Simultaneous labour efficiency is an important factor affecting the value of the average pay. As such, the existence of a positive feedback EFEMP $\Leftrightarrow \mathrm{APAY}_{t}$ between the labour efficiency and average pay is confirmed. This proves the correctness of the construction of the motivational system in the enterprise. A negative autoregression of the average pay emerges in the equation. Additionally, a positive seasonal fluctuation in the first quarter occurs as well. This probably results from the rule of applying pay rises at the beginning of a calendar year, or from the so-called thirteenth salary.

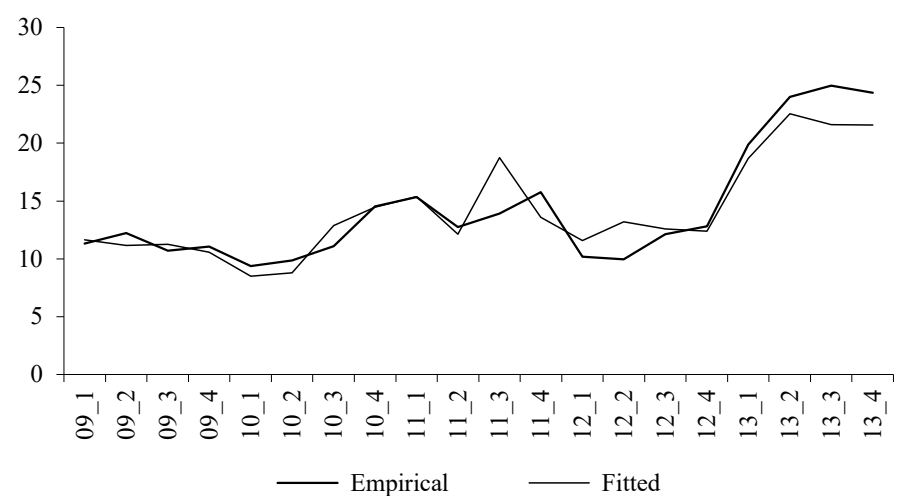

Figure 6. Empirical and fitted values of variable APAY (mln PLN)

Source: own calculations using the GRETL package. 


\section{Equations of payroll and technical devices}

An empirical equation of payroll (PAY) can be considered as the model's final equation, since the value of the net sales income (SNET), simultaneous and delayed by one quarter, is an important explanatory variable. The value of payroll, thus, is dependent on the current and the delayed by 1 quarter values of the variable SNET. There is a negative linear trend of the payroll, which indicates implementation of a savings policy in the enterprise. Also, a negative autoregression of the fourth order confirms the savings aiming at the reduction of the cost of

Table 4. Equation of the dependent variable (Y): PAY

\begin{tabular}{|c|c|c|c|c|c|c|}
\hline Variable & Coefficient & \multirow{2}{*}{\multicolumn{2}{|c|}{$\begin{array}{c}\text { Std. Error } \\
515.7160000\end{array}$}} & t-Statistic & \multicolumn{2}{|c|}{$\mathrm{p}$ value } \\
\hline const & 2014.0200000 & & & 3.9053 & 0.0016 & $* * *$ \\
\hline SPNET & 0.0572653 & \multicolumn{2}{|c|}{0.0121186} & 4.7254 & 0.0003 & $* * *$ \\
\hline SPNET_1 & 0.0988620 & \multicolumn{2}{|c|}{0.0217460} & 4.5462 & 0.0005 & $* * *$ \\
\hline time & -53.1296000 & \multicolumn{2}{|c|}{10.6878000} & -4.9710 & 0.0002 & $* * *$ \\
\hline $\mathrm{dq} 2$ & 438.9640000 & \multicolumn{2}{|c|}{149.2820000} & 2.9405 & 0.0107 & $* *$ \\
\hline PAY 44 & -1.02306 & \multicolumn{2}{|c|}{0.1306250} & -7.8320 & $<0.0001$ & $* * *$ \\
\hline \multicolumn{3}{|l|}{ Mean dependent variable } & \multicolumn{2}{|c|}{ Stand.dev.dep.variable } & \multicolumn{2}{|c|}{414.662300} \\
\hline Sum squared resid. & \multicolumn{2}{|c|}{378451.800000} & \multicolumn{2}{|c|}{ S.E. of regression } & \multicolumn{2}{|c|}{164.414900} \\
\hline R-squared & \multicolumn{2}{|c|}{0.884157} & \multicolumn{2}{|c|}{ Adjusted R-squared } & \multicolumn{2}{|c|}{0.842785} \\
\hline $\mathrm{F}(5,14)$ & \multicolumn{2}{|c|}{21.370750} & \multicolumn{2}{|c|}{$\mathrm{p}$-value for F-test } & \multicolumn{2}{|c|}{$4.25 \mathrm{e}-06$} \\
\hline Log likelihood & \multicolumn{2}{|c|}{-126.859900} & \multicolumn{2}{|c|}{ Crit. Inform. Akaike } & \multicolumn{2}{|c|}{265.719800} \\
\hline Crit.Bayes. Schwarz & \multicolumn{2}{|c|}{271.694200} & \multicolumn{2}{|c|}{ Crit. Hannan-Quinn } & \multicolumn{2}{|c|}{266.886000} \\
\hline Autocor.resid.coef.- rho1 & \multicolumn{2}{|c|}{-0.146442} & \multicolumn{2}{|c|}{ Durbin-Watson stat. } & \multicolumn{2}{|c|}{2.185086} \\
\hline
\end{tabular}

Source: own calculations using the GRETL package.

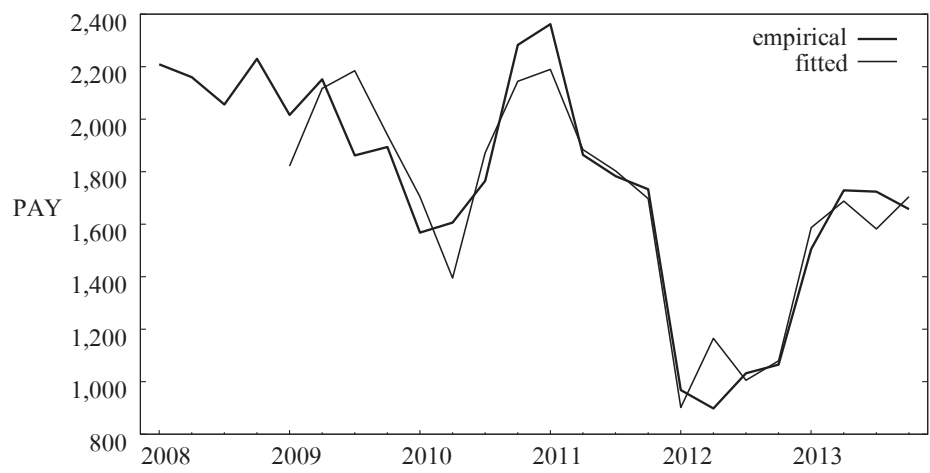

Figure 7. Empirical and fitted values of variable: PAY

Source: own calculations using the GRETL package. 
business activity. The results of the parameters estimation of the equation describing the variable PAY are presented in Table 4.

Figure 7 presents the actual and theoretical values of payroll, calculated on the basis of the empirical equation presented in Table 4 . The equation is characterized by a high description accuracy of the variable PAY. There is no autocorrelation of residuals.

An empirical equation of technical devices (TAL) is presented in Table 5. It is characterized by high description accuracy of the variable TAL, close to $97 \%$ of its total volatility, as well as by lack of autocorrelation of residuals. The actual and theoretical values of technical devices, calculated on the basis of the equation from Table 5, are presented in Figure 8.

Table 5. Equation of the dependent variable (Y): TAL

\begin{tabular}{|l|l|l|l|l|l|}
\hline \multicolumn{1}{|c|}{ Variable } & \multicolumn{1}{c|}{ Coefficient } & \multicolumn{1}{c|}{ Std. Error } & \multicolumn{1}{c|}{ t-Statistic } & \multicolumn{2}{c|}{ p value } \\
\hline const & 35.8274 & 9.59907 & 3.7324 & 0.0014 & $* * *$ \\
\hline DEPR_2 & -0.0575597 & 0.0156778 & -3.6714 & 0.0016 & $* * *$ \\
\hline TAL_1 & 0.73437 & 0.0812774 & 9.0354 & $<0.0001$ & $* * *$ \\
\hline Mean dependent variable & 79.06129 & Stand.dev.dep.variable & 16.78610 \\
\hline Sum squared resid. & 179.4973 & S.E. of regression & 3.073634 \\
\hline R-squared & 0.969665 & Adjusted R-squared & 0.966472 \\
\hline F(2, 19) & 303.6733 & p-value for F-test & $3.79 \mathrm{e}-15$ \\
\hline Log likelihood & -54.30694 & Crit. inform. Akaike & 114.6139 \\
\hline Crit.Bayes. Schwarz & 117.8870 & Crit. Hannan-Quinn & 115.3849 \\
\hline Autocor.resid.coef.- rho1 & -0.088329 & Durbin h-stat. & -0.448140 \\
\hline
\end{tabular}

Source: own calculations using the GRETL package.

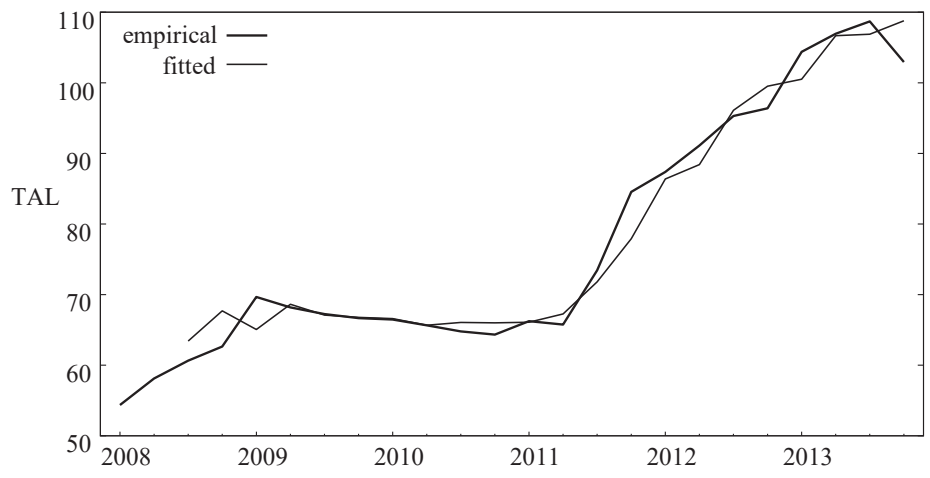

Figure 8. Empirical and fitted values of variable: TAL

Source: own calculations using the GRETL package. 
The structure of the technical devices equation is not very complex. There is a positive autoregression of the first order. Additionally, the value of the net fixed assets' depreciation delayed by two quarters has a negative impact on the level of technical devices. A faster decrease of the employment volume against a decrease of the fixed assets - despite a lack of investments - results in an increase of the technical devices in the enterprise.

\section{Conclusions}

Limited access to statistical data makes the construction of empirical econometric models describing an enterprise a very difficult task. It is unlikely that construction of econometric models is consistent with the theoretical idea. The scarcity of statistical data only allows for the construction of such enterprise' models which are allowed by the available time series. Despite the existing restrictions, the enterprise's empirical econometric model, even a simplified one, if necessary, should be used, because it allows for a highly accurate diagnosis of the company's situation. It provides a chance to precisely prepare decisions. It allows for the construction of sufficiently accurate forecasts for various purposes.

The presented in this work empirical econometric model of a medium-sized company reveals many hidden characteristics. It is clearly visible, that the purpose behind the selection of this company from a large corporation was to improve economic efficiency in this area of business activity. It was achieved by limiting the size of production factors, such as fixed assets and employment volume. As a consequence - despite the lack of investments - technical devices increased. Labour efficiency improved as well, which allowed for the increase of an average pay, by launching the motivational role of the pay. The reduction of the company's costs was the ultimate result of the rationalization of the actions, which was attributed to the economic independence of the business entity.

\section{References}

Goldberger, A.S. (1972). Teoria ekonometrii. Warszawa: PWE.

Pawłowski, Z. (1971). Modele ekonometryczne równań opisowych. Warszawa: PWN.

Pawłowski, Z. (1976). Ekonometryczna analiza procesu produkcyjnego. Warszawa: PWN. 
Sudoł, S. (2002). Przedsiębiorstwo. Podstawy nauki o przedsiębiorstwie. Teorie i praktyka zarządzania. Toruń: TNOiK.

Wiśniewski, J.W., Zieliński, Z. (1989). Ekonometria, cz. II. Toruń: UMK.

Wiśniewski, J.W. (2003). Ekonometryczny model małego przedsiębiorstwa. Toruń: GRAVIS.

Wiśniewski, J.W. (2009). Mikroekonometria. Toruń: Wydawnictwo Naukowe UMK.

Wiśniewski, J.W. (2011). Dylematy podwójnej metody najmniejszych kwadratów w mikromodelu ekonometrycznym (pp. 523-530). In: Modelowanie i prognozowanie gospodarki narodowej. Prace i Materiały Wydziału Zarządzania Uniwersytetu Gdańskiego nr 4/8, Sopot.

Wiśniewski, J.W. (2016). Microeconometrics in Business Management. Chichester: John Wiley \& Sons, Ltd. 